\title{
Gold Recovery from Electronic Waste by Pressure Oxidation
}

\author{
Andrea Alzate 1 , María Esperanza López ${ }^{2}$, Claudia Serna ${ }^{3}$, Oberlando Gonzalez ${ }^{4}$ \\ ${ }^{1,2,3}$ GIPIMME Research Group, Department of Materials Engineering, University of Antioquia, \\ CL 70 52-2, Medellín-Colombia \\ andreaalzatenaranjo@gmail.com; esperanza.lopez@udea.edu.co; Claudia.serna@udea.edu.co \\ 1, ${ }^{4}$ Ingeniería, Suministros y Montajes S.A.S, INSUMON S.A.S, CL 36 36-9, Medellín-Colombia \\ insumon@gmail.com
}

\begin{abstract}
In this study, a pressure oxidative system with ammonium persulfate $\left(\mathrm{NH}_{4}\right)_{2} \mathrm{~S}_{2} \mathrm{O}_{8}$ was developed in order to recover nonleaching gold from electronic waste. The effects of $\left(\mathrm{NH}_{4}\right)_{2} \mathrm{~S}_{2} \mathrm{O}_{8}$ concentration $(0.66-1.31 \mathrm{M})$, pressure $(0-103 \mathrm{kPa})$ and liquid/solid ratio $(15-25 \mathrm{~mL} / \mathrm{g})$ on the recovery of gold were studied in two different levels through a full factorial $2^{3}$ experimental design. The optimum conditions for gold recovery were established in $0.66 \mathrm{M}, 103 \mathrm{kPa}$ and $25 \mathrm{~mL} / \mathrm{g}$ for a reaction time of 5 minutes. With these conditions the metallic substrate $(\mathrm{Cu}, \mathrm{Fe}$, and $\mathrm{Ni}$ ) was oxidized and gold was recovered as a fine coating in a 99.36\%. The resulting solution was treated with a precipitation process to produced non-pollutants by-products $\left(\mathrm{CuSO}_{4}: 5 \mathrm{H}_{2} \mathrm{O}_{(\mathrm{C})} ; \mathrm{FeSO}_{4}: 7 \mathrm{H}_{2} \mathrm{O}_{(\mathrm{C})} ; \mathrm{NiSO}_{4}: 7 \mathrm{H}_{2} \mathrm{O}_{(\mathrm{C})}\right)$
\end{abstract}

Keywords: Gold recovery, Pressure oxidation, Ammonium persulfate, Electronic waste (e-waste)

\section{Introduction}

Recovery of gold from secondary sources has been thoroughly studied in the last few years due to the increase in generation of electronic waste (e-waste). This secondary source contains large quantities of gold and base metals $(\mathrm{Cu}, \mathrm{Ni}$, $\mathrm{Fe}$ ) [1]. The proper metal extraction from e-waste is an important issue from the point of view of mineral shortage and environmental care to avoid pollutants recycling methods. Nowadays, the hydrometallurgical methods available to recover gold from e-waste focus on the total leaching of metallic fraction [2]. In this regard, leaching studies focus on the use of strong acids $\left(\mathrm{HCl}, \mathrm{HNO}_{3}, \mathrm{H}_{2} \mathrm{SO}_{4}\right)$ and oxidative reagents (Cyanide, thiourea, halide, nitrate, iodide, and thiosulfates) [3]-[5]. Leaching process involves time consuming stages to reach the total metal dissolution. Leaching of gold and silver from printed circuit boards (PCBs) with cyanide, nitric acid and thiosulfate has been performed with reaction times greater than 2 hours [6]. In addition, extensive stages of purification include cementation, solvent extraction, precipitation or coagulation demand recovering the metal of interest from the solution [7]. Besides, cyanide, thiourea, halides and some strong acids are recognized by its toxic potential, low chemical stability and environmental problems due to inadequate manipulation [2]. Developing suitable process capable to reduce reaction time and reagents toxicity has become one of the main challenges in e-waste management [8]. In recent years, some processes suggest the implementation of pressure leaching to reduce reaction time in metal extraction [9], [10] and the use of environmentally friendly agents to recover gold and base metals from ewaste [11], [12].

Pressure oxidative process have been used to recover metals as copper, tungsten, vanadium and molybdenum reaching several advantages include reaction time reduction, low temperature, high extraction and the elimination of oxygen supply [9], [10], [13]. Furthermore, autoclave oxidation was investigated to co-treat electronic and pyrite $\left(\mathrm{FeS}_{2}\right)$ waste for extraction of metals from electronic waste [14].

Alternative environmental agents to extract non-leaching gold have been studied to recover gold from e-waste. Agents as potassium persulfate $\left(\mathrm{K}_{2} \mathrm{~S}_{2} \mathrm{O}_{8}\right)$ [11] and cupric chloride $\left(\mathrm{CuCl}_{2}\right)$ [12] were used to oxidize and leach the metal substrate $(\mathrm{Ni}, \mathrm{Fe}$, and $\mathrm{Cu})$ where gold was superficially associated as coating [12]. The selective leaching of the substrate permitted gold recovery in a solid particulate state [11], [12]. Due to the implementation of partial base metals oxidation and the elimination of gold leaching, it was possible to reduce reaction time avoiding purification stages and achieving the $98 \%$ in $\mathrm{Au}$ recovery with minimum formation of pollutants by-products or total agent regeneration [11], [12]. Despites its great advantages, persulfate and cupric chloride oxidative systems to recover non-leaching gold from e-waste have not been extensively investigated. 
In this study, a pressure oxidative system with ammonium persulfate $\left(\mathrm{NH}_{4}\right)_{2} \mathrm{~S}_{2} \mathrm{O}_{8}$ was developed in order to recover non-leaching gold from e-waste. The effects of $\left(\mathrm{NH}_{4}\right)_{2} \mathrm{~S}_{2} \mathrm{O}_{8}$ concentration $(0.66-1.31 \mathrm{M})$, pressure $(0-103 \mathrm{kPa})$ and liquid/solid ratio $(15-25 \mathrm{~mL} / \mathrm{g})$ on the recovery of gold were studied in two different levels through a full factorial $2^{3}$ experimental design. Optimum conditions for Au recovery were established. With these conditions the selective oxidation of the substrate ( $\mathrm{Fe}, \mathrm{Ni}$ and $\mathrm{Cu}$ ) was effectively performed due to the formation of strong oxidative ions and the increase of oxygen partial pressure. This process aimed at releasing solid gold from the oxidized substrate reducing reaction time and pollutants by-products.

\section{Experimental}

\subsection{Materials and reagents}

Waste of computer memory boards supplied by a local recycling company was the sample used. A total amount of 30 end-of-life computer memory boards were selected by reference, shape, weight, superficial distribution of gold and manufacturer to ensure sample homogeneity and statistical significance. Computer memory boards with an average weight of $16.01 \mathrm{~g}$ were used for chemical characterization, pressure oxidation and gold recovery tests without grinding stages.

A sample of $48.00 \mathrm{~g}$ was used to determine the amount of gold and metal substrate $(\mathrm{Fe}, \mathrm{Ni}, \mathrm{Cu})$ at a superficial level by chemical digestion using aqua-regia [6], [15] followed by microwave plasma atomic emission spectroscopy (MP-AES, AGILENT 4100) (Table 1). After chemical characterization, aqueous commercial grade ammonium persulfate $(\geq 98 \%$ $\left.\left(\mathrm{NH}_{4}\right)_{2} \mathrm{~S}_{2} \mathrm{O}_{8}\right)$ with a water solubility of $850 \mathrm{~g} / \mathrm{L}$ at $25^{\circ} \mathrm{C}$ [16] and $6.87 \%$ of active oxygen [9] was the selected environmetal reagent used to produce sulfate ions $\left(\mathrm{SO}_{4}^{-}\right)$and active oxygen. The produced sulfate ions and oxygen generated a system of oxidative reactions that partially leached the metal substrate breaking the Au-Cu-Ni-Fe bond and allowing gold to be extracted in its original non-leaching state. The system of oxidative reactions was catalyzed increasing the partial pressure of oxygen with an autoclave.

Table 1: Chemical composition of waste computer memory boards.

\begin{tabular}{|l|l|l|l|l|}
\hline Element & $\mathrm{Cu}($ wt.\%) & $\mathrm{Fe}($ wt.\%) & $\mathrm{Ni}(\mathrm{wt} . \%)$ & $\mathrm{Au}(\mathrm{mg} / \mathrm{kg})$ \\
\hline Content & 6.997 & 0.976 & 0.873 & 624.274 \\
\hline
\end{tabular}

\subsection{Gold recovery by pressure oxidation}

Recovery of gold was reached oxidizing the metal substrate $(\mathrm{Fe}, \mathrm{Ni}$, and $\mathrm{Cu}$ ) where gold was superficially associated as coating. Substrate oxidation was performed using different concentration $(0.66-1.31 \mathrm{M})$ of ammonium persulfate $(\geq 98 \%$ $\left.\left(\mathrm{NH}_{4}\right)_{2} \mathrm{~S}_{2} \mathrm{O}_{8}\right)$ with a liquid solid rate variation between $15-25 \mathrm{~mL} / \mathrm{g}$. The solutions were prepared in glass vessels $(400 \mathrm{~mL}$ nominal capacity) with deionized water by heating and stirring at boiling point and reagent incorporation. During solutions preparation was produced active oxygen (Eq.1) and reached the complete speciation of persulfate $\left(\mathrm{S}_{2} \mathrm{O}_{8}\right)^{2-}$ in the interest oxidative anion $\left(\mathrm{SO}_{4}{ }^{2-}\right.$ ) (Eq.2). (Eq.1) was reported by Turan et al (2015) [9] and (Eq.2) was calculated using HSC Chemistry software (2002) [18].

$$
\begin{gathered}
\left(\mathrm{NH}_{4}\right)_{2} \mathrm{~S}_{2} \mathrm{O}_{8}+\mathrm{H}_{2} \mathrm{O} \rightarrow 2 \mathrm{NH}_{4}\left(\mathrm{HSO}_{4}\right)+\mathrm{O} \\
\mathrm{S}_{2} \mathrm{O}_{8}^{2-}+\mathrm{H}_{2} \mathrm{O} \rightarrow \frac{1}{2} \mathrm{O}_{2}+2 \mathrm{SO}_{4}^{2-}+2 \mathrm{H}^{+}
\end{gathered}
$$

Selected amount of computer memory boards were put into the different solutions and were transferred to a pressure oxidative system (Portable autoclave - Ref 1925X All American), where pressure was increased from 0 to $103 \mathrm{kPa}$ and temperature remains constant at $120^{\circ} \mathrm{C}$. The applied pressure modified the partial pressure of oxygen and increased the oxidative reaction rate [17]. With the pressure increase, the reaction time was reduced from 40 to 5 minutes. During the reaction period, iron, nickel and copper were partially oxidized and gold was released from the substrate. The resulting solutions were precipitated and sulfate by-products were formed and analyzed by X-Ray fluorescence spectroscopy (XRF, THERMO OPTIMIX).

Breaking Fe-Ni-Cu-Au bond was achieved by substrate oxidation and gold was recovered in its original solid state using micro scale washing with a subsequent process of filtration. Au recovery was calculated based on the initial gold 
content in the scrap and the kinetics was determined measuring the time dependent release of gold at predetermine intervals $(5,20,30$, and $40 \mathrm{~min})$. The effects of $\left(\mathrm{NH}_{4}\right)_{2} \mathrm{~S}_{2} \mathrm{O}_{8}$ concentration, pressure and liquid solid ratio on the recovery of gold were analyzed and a first order mathematical model was developed. The chemical composition and morphology of the recovered gold and the oxidized substrate were analyzed by scanning electron microscopy (SEM/EDX, JEOL JSM-6490LV).

\subsection{Experimental design}

Study of gold recovery by the pressure oxidative process was performed adopting a full factorial $2^{3}$ experimental design [19]. Combinations of factors and levels were effectuated by duplication to establish the experimental error. The selected factors were A: $\left(\mathrm{NH}_{4}\right)_{2} \mathrm{~S}_{2} \mathrm{O}_{8}$ Concentration, B: Pressure and C: Liquid/solid ratio in two different levels (Table 2).

Table 2: Experimental design, factors whit coded and real levels.

\begin{tabular}{|l|c|c|}
\hline Factors & \multicolumn{2}{|c|}{ Levels } \\
\hline & Low $(-1)$ & High $(+1)$ \\
\hline A: $\left[\left(\mathrm{NH}_{4}\right)_{2} \mathrm{~S}_{2} \mathrm{O}_{8}\right](\mathrm{M})$ & 0.66 & 1.31 \\
\hline B: Pressure $(\mathrm{kPa})$ & 0 & 103 \\
\hline C: Liquid/Solid Ratio $(\mathrm{mL} / \mathrm{g})$ & 15 & 25 \\
\hline
\end{tabular}

Sixteen experiments were randomly performed giving as response the recovery of gold that was statistically analyzed using Design Expert software (2015) [20]. The significance of the effects and its interactions over the response was evaluated using analysis of variance (ANOVA) where p-values were generated to prove the null hypothesis with a confidence level of $95 \%(\alpha=0.05)$. An empirical first order equation was developed to evaluate the significance of the factors $(\mathrm{A}, \mathrm{B}, \mathrm{C})$ on the Au recovery. The equation was established considering the regression linear model of three factors with fixed effects (Eq.3) [19], [21].

$$
y=\beta_{0}+\beta_{1} x_{1}+\beta_{2} x_{2}+\beta_{3} x_{3}+\beta_{12} x_{1} x_{2}+\beta_{13} x_{1} x_{3}+\beta_{23} x_{2} x_{3}+\beta_{123} x_{1} x_{2} x_{3}
$$

\section{Results and discussions}

\subsection{Effects of concentration, pressure and liquid/solid ratio on the recovery of gold}

The effects of $\left(\mathrm{NH}_{4}\right)_{2} \mathrm{~S}_{2} \mathrm{O}_{8}$ concentration, pressure and liquid solid ratio on the recovery of gold were analyzed running the sixteen experiments of the full factorial design. The experiment design layout with the actual levels of each factor is shown in table 3 . The standard deviation of the response (Recovery of gold) was calculated to be $\leq 0.73 \%$. The maximum recovery of gold $(99.36 \% \pm 0.45)$ was reached over 5 minutes at point $(-1,+1,+1)$ where pressure was increased at $103 \mathrm{kPa}$ and $\left(\mathrm{NH}_{4}\right)_{2} \mathrm{~S}_{2} \mathrm{O}_{8}$ concentration remains at the lowest level of $0.66 \mathrm{M}$ with an $\mathrm{L} / \mathrm{S}$ ratio of $25 \mathrm{~mL} / \mathrm{g}$. In table 4 , the ANOVA for the model is shown. All linear effects and interactions were statistically significant with $p$-values $\leq 0.05$.

Table 3: Experimental design layout for gold recovery.

\begin{tabular}{|c|c|c|c|c|c|}
\hline Exp & \multicolumn{3}{|c|}{ Factors with actual levels } & \multicolumn{2}{|c|}{ Responses } \\
\hline \multirow[b]{2}{*}{$\mathrm{N}_{0}$} & $\mathrm{~A}$ & $\mathrm{~B}$ & $\mathrm{C}$ & \multirow{2}{*}{$\begin{array}{l}\text { Recovery of gold } \\
(\%)\end{array}$} & \multirow{2}{*}{$\begin{array}{l}\text { Reaction time } \\
\text { (min) }\end{array}$} \\
\hline & {$\left[\left(\mathrm{NH}_{4}\right)_{2} \mathrm{~S}_{2} \mathrm{O}_{8}\right](\mathrm{M})$} & Pressure $(\mathrm{kPa})$ & $\begin{array}{c}\text { L/S Ratio } \\
(\mathrm{mL} / \mathrm{g})\end{array}$ & & \\
\hline $1-2$ & 0.66 & 0 & 15 & $0.00 \pm 0.00$ & 40 \\
\hline $3-4$ & 1.31 & 0 & 15 & $10.67 \pm 0.95$ & 30 \\
\hline $5-6$ & 0.66 & 103 & 15 & $13.83 \pm 0.35$ & 5 \\
\hline $7-8$ & 1.31 & 103 & 15 & $41.32 \pm 0.47$ & 5 \\
\hline $9-10$ & 0.66 & 0 & 25 & $0.00 \pm 0.00$ & 40 \\
\hline $11-12$ & 1.31 & 0 & 25 & $8.82 \pm 1.34$ & 20 \\
\hline $13-14$ & 0.66 & 103 & 25 & $99.36 \pm 0.45$ & 5 \\
\hline $15-16$ & 1.31 & 103 & 25 & $98.79 \pm 1.03$ & 5 \\
\hline
\end{tabular}


Table 4: Analysis of variance (ANOVA) for gold recovery.

\begin{tabular}{|l|r|c|r|r|}
\hline Source & $\begin{array}{c}\text { Sum of } \\
\text { Squares }\end{array}$ & $\begin{array}{c}\text { Degree of } \\
\text { freedom }\end{array}$ & $\begin{array}{c}\text { Mean } \\
\text { Squares }\end{array}$ & p-value \\
\hline Model & 24838.82 & 7 & 3548.40 & $<0.0001$ \\
\hline A- $\left[\left(\mathrm{NH}_{4}\right)_{2} \mathrm{~S}_{2} \mathrm{O}_{8}\right]$ & 538.36 & 1 & 538.36 & $<0.0001$ \\
\hline B- Pressure & 13665.03 & 1 & 13665.03 & $<0.0001$ \\
\hline $\mathrm{C}-\mathrm{L} / \mathrm{S}$ Ratio & 4980.48 & 1 & 4980.48 & $<0.0001$ \\
\hline AB & 13.82 & 1 & 13.82 & 0.0009 \\
\hline AC & 223.73 & 1 & 223.73 & $<0.0001$ \\
\hline BC & 5245.74 & 1 & 5245.74 & $<0.0001$ \\
\hline ABC & 171.68 & 1 & 171.68 & $<0.0001$ \\
\hline Pure Error & 4.28 & 8 & 0.53 & \\
\hline Corrected Total & 24843.10 & 15 & & \\
\hline
\end{tabular}

The regression model that describes the recovery of gold by pressure oxidation with $\left(\mathrm{NH}_{4}\right)_{2} \mathrm{~S}_{2} \mathrm{O}_{8}$ was established calculating the coefficients for each factor and developing a first order equation (Eq.4). The Predicted R-Squared of 0.9993 was in reasonable agreement with the adjusted R-Squared of 0.9997 with a difference $\leq 0.20$, and the coefficient of determination $\left(\mathrm{R}^{2}=0.9998\right)$ proved that the $99.98 \%$ of the variability in the response has been explained by the model.

$$
\mathrm{Au} \text { recovery }=34.10+5.80 \mathrm{~A}+29.22 \mathrm{~B}+17.64 \mathrm{C}+0.93 \mathrm{AB}-3.74 \mathrm{AC}+18.11 \mathrm{BC}-3.28 \mathrm{ABC}
$$

Equation 4 shows that the linear factors $(\mathrm{A}, \mathrm{B}$ and $\mathrm{C})$ and the interactions $(\mathrm{AB})$ and $(\mathrm{BC})$ had a positive effect on the recovery of gold while the $(\mathrm{AC})$ interaction had a negative influence. Positive sign of $\mathrm{A}, \mathrm{B}$ and $\mathrm{C}$ indicates that the increment of concentration, pressure and L/S ratio positively influenced the oxidation of the substrate allowing the release of gold in its solid state. This is explained by the following mechanisms:

- $\quad$ Formation of strong oxidative ions $\left(\mathrm{SO}_{4}{ }^{2-}\right)$

- Delivery of active oxygen from the $\left(\mathrm{NH}_{4}\right)_{2} \mathrm{~S}_{2} \mathrm{O}_{8}$

- Formation of $\left(\mathrm{O}_{2}\right)$ by thermal decomposition

- Fast transference and dissolution of oxygen in the aqueous system by partial pressure increase

These mechanisms permitted the rapid formation of soluble oxides include $\mathrm{CuFeO}_{2}$ with an equilibrium constant greater than zero $\left(\operatorname{LogK}{ }_{\left(95^{\circ} \mathrm{C}\right)}=4.45\right)$ and soluble sulfates includes $\left(\left(\mathrm{FeSO}_{4}\right)^{+}\right.$and $\left(\mathrm{NiSO}_{4}(\mathrm{a})\right)$ [22]. The equilibrium constant for this sulfates were established in $\left(\operatorname{LogK}\left(95^{\circ} \mathrm{C}\right)=3.44\right)$ and $\left(\operatorname{LogK}{ }_{\left(95^{\circ} \mathrm{C}\right)}=3.06\right)$ respectively [18]. Oxidation of metal substrate permitted to break the $\mathrm{Fe}-\mathrm{Ni}-\mathrm{Cu}-\mathrm{Au}$ bond without leaching of $\mathrm{Au}$ from the sample. Release of solid particulate gold was achieved after removing the sample from the reactor and applying a micro scale pressure washing. Plots were generated for the combination of three factors with actual values where the third factor was fixed at the highest level. Figures $1 \mathrm{a}, 1 \mathrm{~b}$ and $1 \mathrm{c}$ show a red region where recoveries of gold were greater than $98 \%$. This can be achieved under combined $\left(\mathrm{NH}_{4}\right)_{2} \mathrm{~S}_{2} \mathrm{O}_{8}$ concentration ranging from 0.66 to $1.31 \mathrm{M}$ with a pressure of $103 \mathrm{kPa}$ and $\mathrm{L} / \mathrm{S}$ ratio of $25 \mathrm{~mL} / \mathrm{g}$.

\subsection{Recovery of gold at optimum conditions}

The optimum conditions for gold recovery by pressure oxidation were established in $0.66 \mathrm{M}, 103 \mathrm{kPa}$ and $25 \mathrm{~mL} / \mathrm{g}$ for a reaction time of 5 minutes. With these conditions the partial oxidation of $\mathrm{Fe}, \mathrm{Ni}$ and $\mathrm{Cu}$ was reached. The oxidation broke the $\mathrm{Fe}-\mathrm{Ni}-\mathrm{Cu}-\mathrm{Au}$ bond and solid gold was removed from the substrate with a process of micro washing and filtration. Gold was recovered as a fine coating in a $99.36 \%$ and the resulting solution was treated with a precipitation process to produced sulfates by-products. The generated sulfates were chemical characterized by X-Ray fluorescence spectroscopy (XRF) and the results are shown in table 5. The precipitated sulfate compound was determined by Medusa software (2010) 
[22] giving as result a mix of metallic sulfates with similar formation probability $\left(\mathrm{CuSO}_{4}: 5 \mathrm{H}_{2} \mathrm{O}_{(\mathrm{C})}(\mathrm{LogK}=2.64)-\right.$ $\mathrm{FeSO}_{4}: 7 \mathrm{H}_{2} \mathrm{O}_{(\mathrm{C})}(\operatorname{LogK}=2.21)-\mathrm{NiSO}_{4}: 7 \mathrm{H}_{2} \mathrm{O}_{(\mathrm{C})}(\operatorname{LogK}=2.36)$.

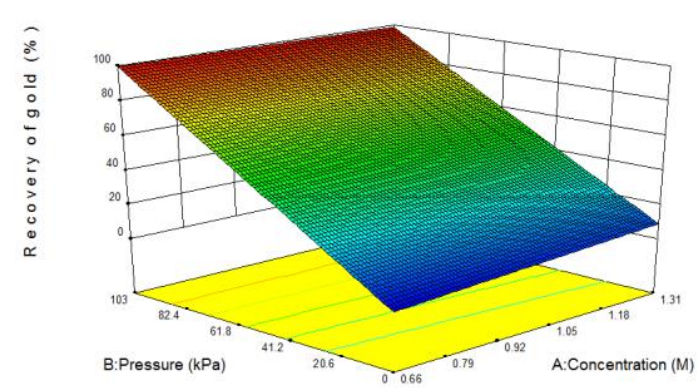

(a)

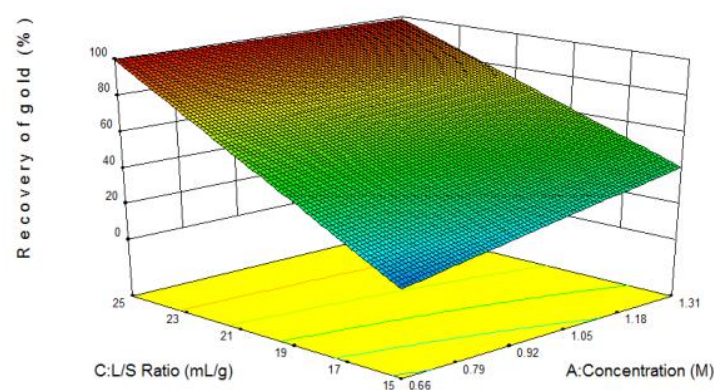

(b)

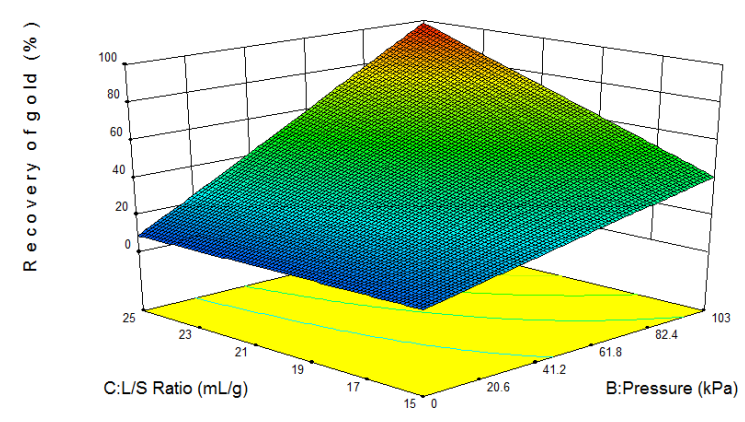

(c)

Fig. 1: Plots of Au recovery (a) A: $\left[\left(\mathrm{NH}_{4}\right)_{2} \mathrm{~S}_{2} \mathrm{O}_{8}\right]$ and B: Pressure with $\mathrm{C}=25 \mathrm{~mL} / \mathrm{g}$, (b) A: $\left[\left(\mathrm{NH}_{4}\right)_{2} \mathrm{~S}_{2} \mathrm{O}_{8}\right]$ and C: $\mathrm{L} / \mathrm{S}$ ratio whit B=103 $\mathrm{kPa},(\mathrm{c}) \mathrm{B}$ : Pressure and $\mathrm{C}$ : $\mathrm{L} / \mathrm{S}$ ratio with $\mathrm{A}=1.31 \mathrm{M}$.

Table 5: Chemical composition of the generated sulfates after oxidation reaction.

\begin{tabular}{|l|l|l|l|l|}
\hline Element & $\mathrm{SO}_{3}$ & $\mathrm{Cu}$ & $\mathrm{Fe}$ & $\mathrm{Ni}$ \\
\hline Content (wt.\%) & 96.53 & 1.76 & 0.74 & 0.53 \\
\hline
\end{tabular}

The Au recovered and the oxidized substrate were analyzed by scanning electron microscopy (SEM/EDX) in order to evaluate chemical composition and morphology. The results are presented in Figure 2 and 3. Pure gold was removed as a fine coating (Figure 2a) from the substrate (Figure 3a). This finding can be compared with the obtained by Barbieri et al., (2010) [12] using $\mathrm{CuCl}_{2}$. EDX was performed in different $\mathrm{Au}$ and substrate samples with replication in five different points. Figure $2 \mathrm{~b}$ shows the grade of purity for Au removed at the optimized levels while Figure $3 \mathrm{~b}$ shows that Ni and Fe were firstly oxidized and $\mathrm{Cu}$ was partially corroded.

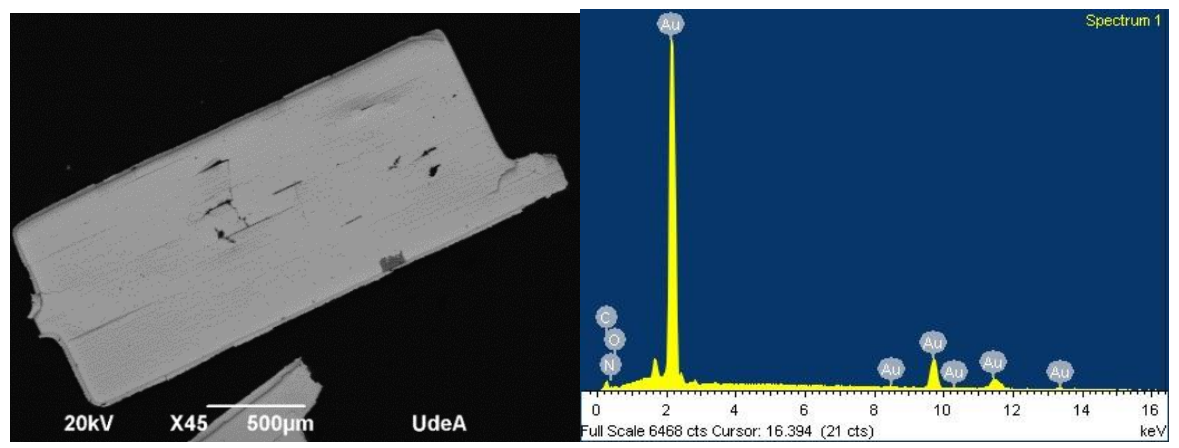

(a)

(b)

Fig. 2: SEM analysis for Au recovery (a) Fine coating of Au, (b) EDX spectrum for Au recovered. 


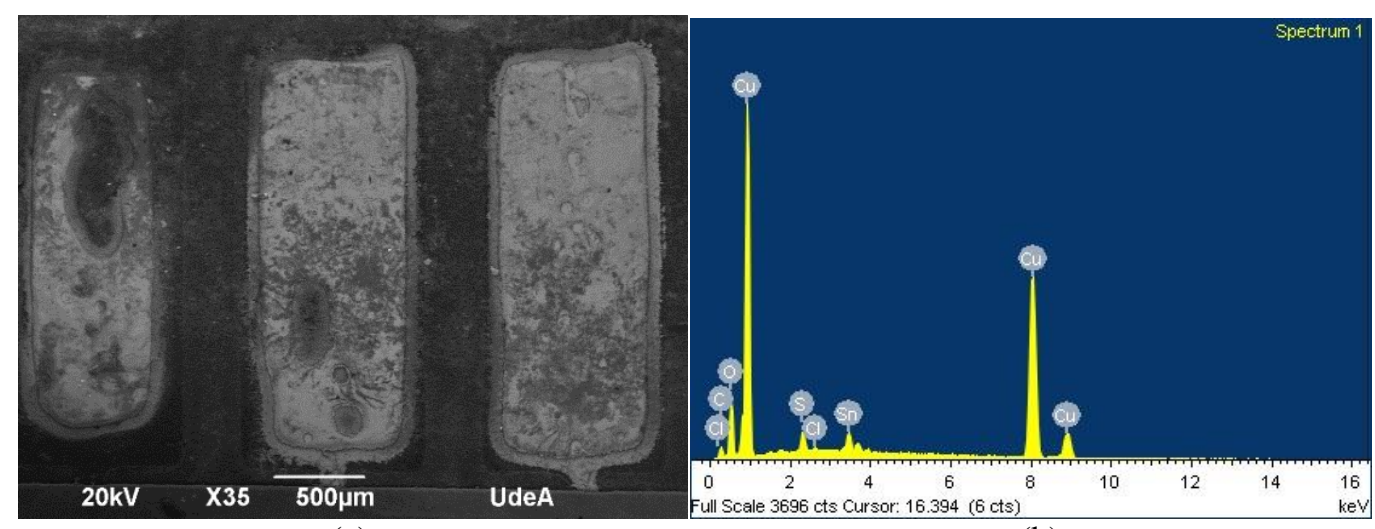

(a)

(b)

Fig. 3: SEM analysis for the oxidized substrate (a) Substrate after pressure oxidation, (b) EDX spectrum for oxidized substrate.

\section{Conclusion}

Gold was recovered from electronic waste (e-waste) by a pressure oxidation system with commercial grade ammonium persulfate $\left(\left(\mathrm{NH}_{4}\right)_{2} \mathrm{~S}_{2} \mathrm{O}_{8}\right)$. The parameters that determined the recovery of gold were studied through $2^{3}$ full factorial experimental design. All the linear factors and interactions were statistically significant with p-values $<0.05$. The optimum values for $\left(\mathrm{NH}_{4}\right)_{2} \mathrm{~S}_{2} \mathrm{O}_{8}$ concentration, pressure and $\mathrm{L} / \mathrm{S}$ ratio were established in $0.66 \mathrm{M}, 103 \mathrm{kPa}$ and $25 \mathrm{~mL} / \mathrm{g}$ for a reaction time of 5 minutes. In that time, the oxidative partial dissolution of substrate took place breaking the Fe-Ni-Cu-Au bond, and non-leaching gold was recovered in a $99.36 \%$. The development of a first order equation for the prediction of Au recovery proved that the $99.98 \%$ of the variability in the response has been explained by the model. The system for Au recovery was implemented increasing the partial pressure of the delivered active oxygen from $\left(\mathrm{NH}_{4}\right)_{2} \mathrm{~S}_{2} \mathrm{O}_{8}$ and the oxygen formatted by thermal decomposition. Both mechanisms had a positive impact in the reduction of total reaction time. $\mathrm{CuSO}_{4}: 5 \mathrm{H}_{2} \mathrm{O}_{(\mathrm{C})}$, $\mathrm{FeSO}_{4}: 7 \mathrm{H}_{2} \mathrm{O}_{(\mathrm{C})}, \mathrm{NiSO}_{4}: 7 \mathrm{H}_{2} \mathrm{O}_{(\mathrm{C})}$ were formatted as by-products after the oxidative reaction. These sulfates could be reincorporate to the supply chain allowing a more effective environmental process. The findings presented in this paper shows that the proposed system (Pressure oxidation with $\left.\left(\mathrm{NH}_{4}\right)_{2} \mathrm{~S}_{2} \mathrm{O}_{8}\right)$ reduced significantly the reaction time and the formation of contaminant by-products and can be applied as an optimum process to recover gold from e-waste.

\section{Acknowledgements}

The authors would like to sincerely acknowledge the national fund for financing of science, technology and innovation (FRANCISCO JOSE DE CALDAS) (Project $\mathrm{N}_{0}$ FP44842-591-2014), the committee for research development of Antioquia University (CODI) (Project N 0 PRG-2014-779) and the University of Antioquia sustainability strategy (2014-2015) for the financial support to successfully develop this research. The authors would also like to thank the Colombian companies INSUMON S.A.S and LITO S.A.S for providing samples, staff and facilities for the experimental tests.

\section{References}

[1] E. Y. Yazici and H. Deveci, "Ferric sulphate leaching of metals from waste printed circuit boards," International Journal of Mineral Processing, vol. 133, pp. 39-45, 2014.

[2] A. Tuncuk, V. Stazi, A. Akcil, E. Y. Yazici, and H. Deveci, "Aqueous metal recovery techniques from e-scrap: Hydrometallurgy in recycling," Minerals Engineering, vol. 25, no. 1, pp. 28-37, 2012.

[3] N. Naseri Joda and F. Rashchi, "Recovery of ultra fine grained silver and copper from PC board scraps," Separation and Purification Technology, vol. 92, pp. 36-42, 2012.

[4] F.-R. Xiu, Y. Qi, and F.-S. Zhang, "Leaching of Au, Ag, and Pd from waste printed circuit boards of mobile phone by iodide lixiviant after supercritical water pre-treatment," Waste Management, vol. 41, pp. 134-141, 2015.

[5] Y. Zhang, S. Liu, H. Xie, X. Zeng, and J. Li, "Current Status on Leaching Precious Metals from Waste Printed Circuit Boards," Procedia Environmental Sciences, vol. 16, pp. 560-568, 2012.

[6] P. M. H. Petter, H. M. Veit, and A. M. Bernardes, "Evaluation of gold and silver leaching from printed circuit board of cellphones," Waste Management, vol. 34, no. 2, pp. 475-482, 2014.

[7] S. Syed, "Recovery of gold from secondary sources-A review," Hydrometallurgy, vol. 115-116, pp. 30-51, 2012. 
[8] A. Alzate, M. E. López, and C. Serna, "Recovery of gold from waste electrical and electronic equipment (WEEE) using ammonium persulfate," Waste Management, 2016.

[9] M. D. Turan, H. Arslano, and H. S. Altundo, "Journal of the Taiwan Institute of Chemical Engineers Optimization of the leaching conditions of chalcopyrite concentrate using ammonium persulfate in an autoclave system," Journal of the Taiwan Institute of Chemical Engineers, vol. 50, pp. 49-55, 2015.

[10] J. Woon, W. Geun, I. Sung, J. Young, and C. Han, "Journal of Industrial and Engineering Chemistry Recovery of tungsten from spent selective catalytic reduction catalysts by pressure leaching," Journal of Industrial and Engineering Chemistry, vol. 28, pp. 73-77, 2015.

[11] S. Syed, "A green technology for recovery of gold from non-metallic secondary sources," Hydrometallurgy, vol. 82, no. 1-2, pp. 48-53, 2006.

[12] L. Barbieri, R. Giovanardi, I. Lancellotti, and M. Michelazzi, "A new environmentally friendly process for the recovery of gold from electronic waste," Environmental Chemistry Letters, vol. 8, no. 2, pp. 171-178, 2010.

[13] S. Wang, C. Wei, Z. Deng, C. Li, X. Li, J. Wu, M. Wang, and F. Zhang, "Extraction of molybdenum and nickel from Ni-Mo ore by pressure acid leaching," Transactions of Nonferrous Metals Society of China, vol. 23, no. 10, pp. 30833088, 2013.

[14] A. Shibayama, W. Tongamp, B. Altansukh, K. Haga, and A. Hosoi, "Electronic waste treatment: Part 1. Autoclave oxidation-leaching using pyrite waste from mine tailing," Hydrometallurgy, vol. 137, pp. 92-100, 2013.

[15] C.-H. Lee, L.-W. Tang, and S. R. Popuri, "A study on the recycling of scrap integrated circuits by leaching.," Waste management \& research: the journal of the International Solid Wastes and Public Cleansing Association, ISWA, vol. 29, no. 7, pp. 677-685, 2011.

[16] O. Sids and U. Publications, "Persulfates 7727-54-0 : Ammonium Persulfate 7727-21-1 : Potasium Persulfate 7775-271 : Sodium Persulfate," pp. 1-192.

[17] K. G. Thomas, "Pressure oxidation overview," Developments in Mineral Processing, vol. 15, no. C, pp. 346-369, 2005.

[18] HSC Chemistry, Chemical reaction and equilibrium software V. 6.1., Outotec Research Oy, 2002.

[19] D. Montgomery, Design and analysis of experiments, Second Ed. Mexico: Limusa Wiley, 2013.

[20] Design-Expert, Design-Expert, Version 9.0.4.1. Minneapolis: Stat-Ease Inc., 2015.

[21] D. Montgomery, Engineering Statistics. Arizona State University: John Wiley \& Sons, Inc., 2011.

[22] Medusa, Software for chemical equilibrium diagrams. Sweden: Royal institute of technology, 2010. 